\title{
O TRABALHO COLABORATIVO NO CINEMA DE KEN LOACH
}

\author{
Marcos César de Paula Soares ${ }^{1^{*}}$ \\ ${ }^{1}$ Universidade de São Paulo, São Paulo, São Paulo, Brasil
}

\begin{abstract}
Resumo
O artigo parte da análise da cena inicial do filme Eu, Daniel Blake do cineasta inglês Ken Loach para discutir o contexto em que se iniciou a carreira do cineasta, em meio ao debate inglês sobre as heranças do Naturalismo na literatura e no cinema. Em seguida, o artigo se voltará para algumas das consequências práticas desta discussão no que tange aos métodos de trabalho colaborativos adotados pelo diretor para garantir aquilo que ele chama de "autenticidade do retrato da vida das classes trabalhadoras inglesas".
\end{abstract}

Palavras-chave: Ken Loach; Naturalismo; Brecht; Raymond Williams; colaboração.

\begin{abstract}
This article begins by proposing an analysis of the initial sequence of Ken Loach's I, Daniel Blake in order to discuss the context in which the director began his career, in the midst of the English debate on the heritage of Naturalism in literature and film. The article will then reflect on some of the practical consequences of this discussion, especially in relation to the methods of collaborative work employed by the director in order to ensure what he calls the "authenticity of the protrait of the English labouring classes".

Keyword: Ken Loach; Naturalism; Brecht; Raymond Williams; Collaboration;
\end{abstract}

\footnotetext{
"Professor de Literaturas Inglesa e Norte-Americana na Universidade de São Paulo. Possui graduação em Inglês pela Universidade de São Paulo (1990) e doutorado em Estudos Linguísticos e Literários em Inglês pela Universidade de São Paulo (2000). Fez pós-doutorado na Universidade de Yale, EUA (2004) e na Universidade de Columbia, EUA (2012). Seu e-mail é mcpsoare@usp.br. ORCID: 0000-0002-7056-3621.
} 
A cena de abertura do filme Eu, Daniel Blake (2016), do diretor Ken Loach, lançado no Brasil em meio ao debate sobre o desmonte da previdência social, mostra a tela inteiramente negra, na qual vemos os créditos iniciais e ouvimos um diálogo. As vozes são de Amanda, uma assistente social, e Daniel Blake, o protagonista que dá título ao filme. Os dois interlocutores invisíveis debatem o estado de saúde de Blake, que recentemente sofreu um ataque do coração e tenta obter auxílio daquilo que restou do Estado de Bem Social inglês. A entonação da mulher, com sua evidente falta de ênfase, mostra que a leitura de uma lista de questões pré-estabelecidas se transformou em rotina. A banalidade cada vez mais cômica das perguntas, que pretendem descobrir se Blake consegue colocar um chapéu, apertar um botão ou transmitir mensagens simples, beira o absurdo. Blake pede para que eles discutam seu problema de coração, enquanto a assistente social ameaçadoramente insiste que eles sigam o roteiro. A tela ainda está completamente negra. Um novo ponto de inflexão do diálogo se estabelece quando Blake pergunta se Amanda é uma profissional do campo da saúde - uma médica ou enfermeira - e insinua que, segundo rumores, ela é funcionária de uma empresa norte-americana. Ela, por sua vez, evita a pergunta, afirmando que foi contratada pelo governo para lidar com assuntos da área da saúde pública. Tal convergência entre governo e os negócios em âmbito global nos remete daquilo que parecia ser uma ilustração dos sistemas de poder teorizados por Foucault ou dos modelos "racionais-legais" de Weber de volta àquela "última instância determinante", ou seja, à esfera da economia, pois a terceirização do controle de serviços "não essenciais" para o setor privado tem sido uma das "medidas de austeridade" mais frequentes nas últimas décadas de hegemonia neoliberal. E se a tela negra pode ser vista como um emblema paradigmático das dificuldades de formulação de uma estética realista contemporânea, ou, se quisermos seguir Fredric Jameson, da impossibilidade de que, na era do capital financeiro, um aparato sensorial individual possa dar figuração concreta a um sistema complexo de relações econômicas globais ${ }^{1}$, também é verdade que o filme insistirá no lado mais pragmático da questão, a saber, a função econômica da invisibilidade mútua dos dois interlocutores. Trata-se de mostrar a opacidade e a pulverização mais absoluta de qualquer laço de contato ou solidariedade, que transforma interações humanas concretas em simples problemas de corte de gastos.

O filme seguirá a luta de Blake contra os processos de "racionalização" da burocracia socialdemocrata, explorando uma série de situações cada vez mais grotescas, tanto cômicas quanto trágicas, incluindo a transformação de formas contemporâneas de despossessão em atividades econômicas lucrativas (desde a especulação imobiliária em Londres, passando pela proliferação de "cursos de atualização" e o comércio de móveis usados até a prostituição). A edição do filme irá contrastar essa camada de significados, que expõe um estado de miséria social generalizada inaceitável para um dos países mais ricos do mundo (incluindo, talvez pela primeira vez no cinema inglês, o problema da fome), com sequências que demonstram a habilidade de Blake na execução de uma série de tarefas manuais (ele é carpinteiro). Tais sequências, por sua vez, irão produzir um contraste 
com outras em que se mostra o falso profissionalismo dos funcionários do governo, cuja aparência de modernidade conta com a digitalização integral do sistema burocrático, num processo que encobre a precarização do trabalho da própria assistência social, a julgar pela sequência de abertura. Num determinado ponto, Blake será aconselhado a procurar um computador e entrar on-line para requerer formulários especiais para "analfabetos digitais". Em outro momento, passará dias procurando um emprego (para cumprir com a burocracia da previdência) que não pode aceitar (por motivos médicos). Já o fato de que essa série de disparates, que beiram o surreal, seja encenada de maneiras que evitam, novamente seguindo Jameson, tanto as dispersões de uma estética mais propriamente pósmoderna, quanto os impulsos distópicos da ficção-científica, mas, pelo contrário, enfatizam aquilo que os críticos, quando se referem ao trabalho de Loach, têm chamado de "naturalismo rigoroso" 2 pode constituir uma importante descoberta formal para a análise de regimes de trabalho contemporâneos, cuja novidade no tecido da vida cotidiana os filmes ajudariam a catalogar. Ao mesmo tempo, a investigação da gênese do "naturalismo" do trabalho de Loach, sua "autenticidade" no tratamento dos problemas da classe trabalhadora inglesa, como a crítica já apontou inúmeras vezes, pode nos levar a uma compreensão de como tais "efeitos de realidade" só são possíveis a partir de uma prática de trabalho colaborativo com o elenco que o diretor aperfeiçoou desde o início de sua carreira.

A formação específica que deu origem à carreira de Ken Loach nos obriga, entretanto, a sermos mais precisos no emprego do termo "naturalismo" de modo a evitarmos as generalizações comuns em torno de seu uso. Pois o final da década de 1950 e o início dos anos 1960 veem justamente o momento em que se realizou na Inglaterra uma profunda reavaliação das heranças do Naturalismo na literatura e na dramaturgia, tanto da parte da Nova Esquerda (particularmente na obra de Raymond Williams) quanto da parte de uma nova geração de escritores e cineastas cujo trabalho, cobrindo o período entre 1958 e 1964, viria a ser designado como a "British New Wave" (o equivalente inglês às diversas "novas ondas" que introduziam na discussão política e cultural a perspectiva dos jovens rebeldes que protagonizariam os eventos cataclísmicos de 1968). Em parte, essa reavaliação reverteria um diagnóstico anterior. Se na França, seguindo as batalhas que se iniciaram em 1848 e que atingiram seu clímax na Comuna de Paris, alguns dos mais urgentes dilemas estéticos do debate moderno foram inaugurados por escritores ligados ao movimento Naturalista, dentre os quais o mais célebre foi Zola, na Inglaterra a interdição contra o Naturalismo fora abraçada até por Raymond Williams. Em 1952, em seu livro Drama from Ibsen to Eliott, Williams havia afirmado que "o projeto naturalista original de mostrar as pressões determinantes do ambiente sobre a personagem" havia no fim "transformado a sociedade em um tipo de segunda natureza”, numa avaliação que em parte convergia com o notório diagnóstico de Lukács. ${ }^{3}$

Essa sentença contra o Naturalismo se dava justamente num momento em que surgia na Inglaterra um renovado interesse pela vida e cultura das classes trabalhadoras, num momento de uma intensa militância que se organizava para 
enfrentar a ofensiva do capital e do governo para conter o aumento de salários e aumentar a produtividade industrial e, assim, encarar a competição crescente com a Alemanha e o Japão na divisão do mercado mundial. ${ }^{4}$ Tal interesse fez com que dois livros recém-publicados - The Uses of Literacy (1957), de Richard Hoggart, e Culture and Society (1958), de Raymond Williams - se transformassem rapidamente em clássicos que impulsionariam o florescimento cultural e político da Nova Esquerda britânica. Enquanto Williams havia submetido parte importante da tradição conservadora inglesa, de Edmund Burke a Matthew Arnold e F. R. Leavis, ao crivo rigoroso de uma leitura baseada num conceito mais amplo e democrático de cultura, Hoggart havia escrito uma narrativa que mesclava de maneira criativa a sociologia e a autobiografia para descrever os modos de vida de uma comunidade de trabalhadores do norte industrial do país. Sua ênfase recaia na mudança desse modo de vida causada pelo impacto da "cultura de massas" e da relativa "afluência" criada por décadas de governo Conservador desde o início dos anos 50, antes que a Alemanha e o Japão se recuperassem da devastação da Segunda Guerra Mundial. A enorme influência dos dois livros se estendeu ao campo literário, nas peças e romances dos "angry young men", termo designado para nomear um grupo de escritores de origem proletária ativos durante boa parte da década de 1950 (vários deles do norte industrial), cujas obras demonstraram a impaciência dos jovens artistas em relação ao conservadorismo inglês (dentre os dramaturgos, o mais conhecido foi John Osborne, enquanto no campo do romance os escritores mais representativos foram Kingsley Amis, Alan Sillitoe, Stan Barstow, John Braine e Davis Storey). O florescimento - relativamente tardio - do Naturalismo literário inglês encontrava, enfim, toda uma geração de jovens escritores interessados no ponto de vista dos pobres sobre o processo social do período do pós-guerra.

A cultura tradicional das classes trabalhadoras inglesas, vista da perspectiva dos jovens rebeldes, fora forjada a partir das necessidades materiais em comunidades nas quais o confronto contra tais dificuldades contava com laços de solidariedade da coletividade (a família ou os outros trabalhadores, unidos num sentimento comum de resistência e apoio mútuo). Entretanto, há em diversas dessas obras uma mudança de ênfase determinante: no lugar das relações descritas e analisadas em termos das relações de trabalho e dos modos de produção, os novos termos de observação da jovem geração seriam frequentemente ligados à crítica das novas formas de lazer e consumo criadas pela invasão cultural norte -americana e pelas formas de conformismo criadas pelo "consenso" forjado pela administração conservadora desde 1951, e seu tom, entre o elegíaco e o nostálgico, lamentava a morte de uma cultura corroída internamente pelos novos valores.

Foi o trabalho desses novos escritores que formou a base dos filmes da "New Wave” britânica: parte considerável dos jovens diretores fizeram adaptações cinematográficas de romances, peças e contos da nova safra de artistas, em filmes como Look Back in Anger (1958), A Taste of Honey (1961) e The Loneliness of the Long Distance Runner (1962), de Tony Richarson, A Room at the Top (1959), de Jack Clayton, A Kind Of Loving (1962) e Billy Liar (1963), de John Schlesinger, 
Saturday Night and Sunday Morning (1960), de Karel Reiz e This Sporting Life (1963), de Lindsay Anderson. Filmando em locações externas no norte do país e utilizando atores até então desconhecidos e com padrões de beleza pouco convencionais, os jovens diretores procuraram introduzir no cinema inglês toda uma área de experiências até aquele momento tratadas como residuais ou marginais. No conjunto, aquilo que distingue os filmes é sua insistência em tratar das vidas das classes trabalhadoras em zonas industriais do país de modo a destruir a "falsa teatralidade" do cinema comercial inglês e construir modos mais "autênticos" que dessem conta da novidade da matéria abordada. A tentativa, naturalmente, impõe a pergunta a respeito da adequação da novas formas mais "realistas" de expressar as experiências sociais que os filmes pretendem explorar. Já foi afirmado pela melhor crítica sobre o assunto que na quase totalidade dos filmes a ênfase na "dignidade do homem trabalhador" leva a uma resistência de representar as dinâmicas "degradantes" do trabalho industrial em nome de um "realismo moral", a partir do qual se afirmam "valores humanos universais" (conflitos de gerações, problemas matrimoniais, conflitos de ordem sexual, etc.). Utilizando os termos críticos mobilizados poderosamente por Peter Szondi, pode-se dizer que o assunto é épico (coletivo), enquanto a forma permanece essencialmente dramática (âmbito das relações interpessoais). ${ }^{5}$ Ademais, a tentativa de forjar o sentimento de uma nova autenticidade criará, do ponto de vista dos métodos de trabalho adotados na produção dos filmes, uma nova versão dos impasses enfrentados tanto por Stanislávski na Rússia, quanto por seu discípulo, Lee Strasberg, nos Estados Unidos: como treinar atores para retratar convincentemente personagens de um estrato social essencialmente desconhecido para a maioria deles? Como veremos mais adinte, Loach criará uma solução original para esse problema com base numa prática específica de trabalho colaborativo.

Já no que tange a questão do foco narrativo, aspecto técnico central na configuração de "autenticidade" no tratamento do "Outro", os filmes da "British New Wave" se pautam pela adoção generalizada daquilo que se chamou de ponto de vista do "scholarship boy" (o "bolsista"), figura típica da paisagem descrita por Hoggart, o jovem de classe trabalhadora que abandona suas origens e que olha com nostalgia o mundo mais "genuíno" da infância distante (no caso de Hoggart, e até mesmo de Raymond Williams, através da entrada na vida universitária leia-se Oxford ou Cambridge - promovida pelas políticas de meritocracia dos Conservadores para selecionar jovens talentos). Assim, o ponto de vista dos filmes é invariavelmente pautado pelo jovem que sonha com a possibilidade - real ou imaginária - da mobilidade social e cuja "individualidade" - critério central de constituição de personagens dramáticos - se forma a partir da tentativa de escapar das "massas" de modo a forjar um olhar particular sobre o mundo. À essa "universalização" dos temas corresponde, em sentido oposto, uma tentativa de criar um certo grau de "realismo" compensatório, expresso principalmente nas sequências de transição entre núcleos dramáticos que mostram fábricas e bairros operários: o sentido de classe é, assim, externalizado e transformado em iconografia ou "atmosfera". E é nessas tomadas que se busca construir uma 
síntese entre "realismo" (cujo sentido depende de certa fé numa "ontologia da imagem fotográfica" expresso na crueza e na feiura proposital dos cenários) e sua superação através de certo "realismo poético", expresso frequentemente pelo uso de filtros nas tomadas longas que fazia com que as paisagens proletárias fossem envoltas em névoas, brumas, nuvens, poluição ou fumaça das fábricas ${ }^{6}$ que lhes suavizavam o contorno.

Da perspectiva da crítica, é preciso notar que a grande maioria das resenhas e ensaios escritos à época de lançamento dos filmes, especialmente aqueles publicados na revista Movie (tipo de publicação equivalente aos Cahiers du ciné$m a$ na França) se esforçou para apontar para a incongruência entre argumento (dramático) e ambientação (proletária). ${ }^{7}$ Mas também é verdade que, na quase totalidade dos casos, a solução encontrada para a "falta de realismo" dos filmes é a recomendação do método francês, ou seja, a estética realista de Bazin. Num dos ensaios mais influentes escritos na época, o crítico Peter Graham, depois de uma avaliação devastadora dos filmes ingleses, já evidente no título - "Por que os bons filmes ingleses são tão ruins?" - aconselhava:

É esse tipo de atitude em relação à apresentação da realidade que prejudica grande parte de A Kind of Loving. Se Schlesinger pretendia fazer uma adaptação fiel do romance, deveria ter escolhido um estilo mais flexível do que essa versão rebaixada da montagem clássica, que permite apenas uma interpretação da realidade, a do diretor, e que exclui todas as outras. Tal abordagem era ideal para os propósitos de um diretor estilizado como Eisenstein, mas não é de modo algum mais realista. Um estilo mais abrangente, caracterizado pela composição em profundidade de campo, pela ênfase na presença física do ator no cenário e pela continuidade da ação, permite que o espectador interprete a ação diante dele de diversos modos, todos válidos. O equivalente a esse estilo é a própria vida, em que ações e incidentes são interpretados de maneiras diversas por pessoas diferentes. André Bazin, o defensor desse estilo, afirmou corretamente que desse modo o filme ganha em ambiguidade, em múltiplos níveis de interpretação e significado, áreas que até então haviam sido privilégio do romance. ${ }^{9}$

Além da redução da montagem eisensteniana a "estilo", sem perceber seu alcance histórico, e a troca de uma ortodoxia (a montagem clássica) por outra (a profundidade de campo e o plano-sequência), vale a pena apontar para a total ausência de reflexão teórica ou prática acerca da repercussão de Brecht sobre a cena teatral inglesa, praticamente nula a julgar pelas resenhas, embora tanto Raymond Williams quanto Ken Loach insistam em apontar o impacto do dramaturgo alemão sobre sua formação, especialmente a partir de 1956, ano em que o Berliner Ensemble passa por Londres. É a partir desse contexto e dessa perspectiva que devemos encarar a mudança de opinião de Raymond Williams sobre o Naturalismo, como veremos mais adiante. Já do ponto de vista da ênfase na colaboração, aspecto constitutivo obrigatório para uma arte que se constrói a partir do trabalho coletivo de artistas e técnicos, a importação da teoria francesa ajudou a ofuscar a discussão, por exemplo, sobre a relação produtiva entre diretores e escritores, pois a tendência idealista era reforçar o papel de auteur do di- 
retor, que se sobrepujava sobre a totalidade de seus colaboradores para imprimir sua "marca pessoal" no filme.

Mas antes de avançar é preciso fazer um pequeno desvio de rota para apontar para um momento de inflexão crucial dessa narrativa: a eleição do Primeiro Ministro Trabalhista Harold Wilson em 1964, após um acirrada e agressiva campanha política na qual os estrategistas do Labour Party se inspiraram na campanha de John F. Kennedy em 1960 e que um historiador descreveu como sendo parcialmente baseada na vida de "atores e escritores da New Wave", com Wilson projetando uma imagem de um "rebelde com gostos claramente populares" ${ }^{10}$ As discussões sobre a decadência e a crise do Império e da vida nacional (cada vez mais evidentes após a débâcle britânica em Suez em 1956 e a crise econômica no início dos anos 60) criaram a esperança de que o jovem Wilson, impulsionado pelo clima de euforia jovem que viria a criar a cultura da "Swinging London", encontrasse soluções criativas para a crise após os "treze anos perdidos" de governo Conservador. Tais esperanças foram encampadas também por um grupo de jovens escritores e diretores trabalhando para a televisão pública inglesa, a BBC, dentre os quais Ken Loach no início de sua carreira, que pensava que a televisão, com seu alcance ampliado, poderia ser um veículo apropriado para a extensão de suas sensibilidades socialistas. Esse também foi o momento no qual Raymond Williams fez uma revisão substancial de seu primeiro livro sobre teatro, cujo título é mudado para Drama from Ibsen to Brecht, publicado em 1968. Numa série de entrevistas concedidas aos jovens membros do corpo editorial do periódico New Left Review em 1979, Williams explica que foi o encontro com Brecht que o obrigou a reavaliar suas antigas posições e que o impeliu à revisão do livro, que não se restringia a uma mera adição de um capítulo sobre Brecht, mas a uma completa restruturação do esquema interpretativo do conjunto. ${ }^{11}$ Também foi nessas entrevistas que ele retoma a discussão sobre o Naturalismo e sobre Lukács, cujas conclusões acerca do tema rejeita, admitindo francamente que suas próprias avaliações anteriores haviam sido conservadoras. Williams encampa a noção, que também é a de Brecht, do Naturalismo como o primeiro capítulo da dramaturgia moderna a desenvolver uma pesquisa a respeito do problema de criar formas de cultura e de expressão artística baseadas na perspectiva da classe trabalhadora e na rejeição de explicações metafísicas da vida social:

Minha compreensão do projeto original estava errada. Pois o naturalismo foi parte de um movimento social secular que era progressista e necessário. O principal objetivo do naturalismo foi sua oposição ao super-naturalismo. Eram três as suas ênfases: a insistência primeiramente no secular, em segundo lugar no contemporâneo e em terceiro nos procedimentos científicos da história natural. Em outras palavras, o trabalho que os naturalistas introduziram pertence decisivamente a um projeto liberador $[\ldots] \cdot{ }^{12}$

Williams também concorda com Brecht em seu ataque à noção de empatia que caracterizava a dramaturgia naturalista (noção encampada pela totalida- 
de dos diretores da "New Wave" britânica). Também sugere, para o futuro das pesquisas no campo, o desenvolvimento da diferença entre modos "indicativos" (aquilo que é) e "subjuntivos" (aquilo que pode vir a ser) da forma dramática que permitisse que "todos os tipos de futuros alternativos e ações dinâmicas possam ser encenados de modo naturalista", ${ }^{13}$ ou seja, de um modo que abraça um ímpeto investigativo baseado no ponto de vista dos trabalhadores e que considere como genuíno todo experimento formal que ajude a reforçar e clarificar esse ponto de vista. ${ }^{14} \mathrm{O}$ critério passa a ser político e não formalista (a pressuposição de que uma única forma literária possa ter acesso privilegiado à verdade) e o "realismo" passa a ser visto como toda uma forma de pesquisa e conhecimento, baseada numa perspectiva específica, que lhe dá chão histórico e lhe afia o senso crítico. ${ }^{15}$ Ken Loach, por sua vez, que nunca se arvorou à pecha de auteur e nem apostou em suas consequências (a ênfase no elemento autobiográfico na confecção dos enredos), cedo percebeu que o alcance e extensão da pesquisa que se iniciava só poderia dar frutos com sua aliança com parceiros que estivessem mais a par da história da classe trabalhadora britânica: começa, assim, uma parceria de colaboração que duraria mais de uma década com o escritor Jim Allen, um ex-trabalhador da região de Manchester que se tornou dramaturgo e militante socialista.

No ensaio "A defence of realism" (1976), Williams afirmará que uma das primeiras produções da dupla Ken Loach e Jim Allen para a BBC - The Big Flame (1969) - constitui precisamente um exemplo do tipo de abordagem que tem em mente. O filme trata de uma greve histórica de um grupo de trabalhadores das docas de Liverpool em 1967 contra a qual o governo Trabalhista contava com o apoio dos sindicatos convencionais a partir das conclusões do "Devlin Report", um relatório encomendado pelo governo sobre as condições das docas, que recomendava uma ofensiva contra as organizações "não oficiais" de trabalhadores como método para evitar greves. Inicialmente, os passos que levam à greve, as tentativas de negociação entre grevistas, líderes sindicais e representantes oficiais são encenadas de um modo que Raymond Williams chamaria de "modo indicativo", até que um dos líderes dos grevistas introduz o "modo subjuntivo" ao sugerir a "grande chama" do título: e se ao invés de manter os mecanismos defensivos da greve, os trabalhadores resolvessem ocupar as docas? Entretanto, essa "hipótese imaginativa" não é encenada de "modo utópico" (ainda nas palavras de Williams), mas de "modo naturalista", numa fusão entre "os métodos familiares de estabelecer reconhecimento e o métodos alternativos de elaboração de uma hipótese no interior desse reconhecimento, que é então encenada em termos realistas, mas no horizonte de uma possibilidade política imaginada"16.

Se desenvolvermos essa hipótese analítica de Williams a partir do filme de Loach, podemos vislumbrar a gênese daquela descoberta formal à qual nos referimos no início deste artigo: trata-se de um método de encenação que projeta uma hipótese futura a partir da pesquisa sobre experimentos políticos reais em âmbito local e internacional, que servem de base para novas possibilidades imaginadas. Em The Big Flame, por exemplo, as encenações das cenas coletivas dos conselhos e assembleias de trabalhadores mostram um salto substantivo em 
relação aos filmes da geração anterior da "New Wave": o assunto épico encontra sua forma expressiva através da adoção de planos mais abertos, da tipificação dos atores/trabalhadores e da adoção generalizada da narração em cena, no momento em que os líderes resumem fatos ocorridos e fazem análises e propostas. Trata-se, portanto, da adoção de formas expressivas que nasceram a partir de experiências com formas de agitação e propaganda (o chamado "agitprop"), cujo desenvolvimento remonta ao teatro bolchevique durante a Revolução Russa, ${ }^{17}$ mas mantendo os termos políticos específicos da situação analisada. Aqui, como o próprio Ken Loach admitiu, foi a experiência dramaturgica de Jim Allen que alavancou o projeto de modo decisivo. Voltando a Williams, o fato de que no final esse conjunto de hipóteses seja derrotado em termos da ação específica (os líderes são presos) não significa que ele seja derrotado como ideia, de modo que as cenas finais, com as imagens de novos conselhos de trabalhadores e, especialmente, de crianças, mostra que tais hipóteses são retidas como possibilidades futuras (de fato, a greve de Liverpool foi seguida de uma série de outras greves entre motoristas de ônibus, faxineiros e operários da construção civil, ajudando a criar um novo nível de militância na cidade $\left.{ }^{18}\right)$. Ao mesmo tempo, no filme a derrota da greve é parcialmente explicada por uma análise das dinâmicas subjetivas e objetivas da traição de classe (um dos trabalhadores colabora com a polícia), num trabalho de pesquisa histórica que no futuro levaria à produção do extraordinário Terra e Liberdade (1995), provavelmente o primeiro filme da história do cinema a expor uma cuidadosa análise trotskysta do papel da traição de classe na derrota das forças democráticas na Guerra Civil espanhola.

No que se refere ao trabalho envolvido na produção do filme, essa abordagem exige a colaboração entre escritores, diretor e técnicos na pesquisa prática e teórica sobre a história da classe trabalhadora, suas conquistas e derrotas, no nível de detalhamento e profundidade que exige a encenação naturalista (o famoso "excesso de descrição" de que é frequentemente acusado o naturalismo ganha aqui uma função política). Mas também envolve um esforço de refletir sobre as escolhas formais que podem ser utilizadas na lida com tais temas. Dentre essas soluções, a mais eloquente no que se refere ao salto feito por Ken Loach em relação aos cineastas da "New Wave" tem a ver com a escolha de atores e as consequências decorrentes no que tange ao trabalho de direção. Pois Loach é conhecido pelo emprego de atores com pouca ou nenhuma experiência e, em diversos casos, não atores (prática desenvolvida amplamente pelo teatro e cinema soviéticos depois de 1917, assim como pelo Neorealismo italiano) de modo a capturar, nas palavras de Williams, "uma linguagem autêntica por usar o sotaque, as ênfases e o modo de falar de homens reproduzindo situações da vida real". ${ }^{19}$ Tal escolha envolve um número de consequências práticas e técnicas específicas. Em entrevista sobre a produção do filme Kes (1969), notável pela atuação de David Bradley, um adolescente da classe trabalhadora de uma cidade de mineradores no norte do país com nenhuma experiência como ator, Loach explica como chegou aos seus surpreendentes resultados através da colaboração com o ator novato: a adoção de planos mais abertos, de modo a evitar o clima mais intimista geralmente exigido 
por atores mais experientes, que se beneficiam de planos mais fechados que lhes possibilitem exibir sua técnica, criou resultados inesperados até para Loach. Nas palavras do diretor: "A palavra chave nesse tipo de cinematografia é observação. Você observa algo que está acontecendo e não coloca a câmera na cara das pessoas enquanto as coloca nesta ou naquela posição. Você deixa que algo aconteça, dá um passo para trás e observa”. ${ }^{20}$

Tal tentativa de "encenar a autenticidade" tem, por sua vez, uma outra série de consequências práticas, inclusive, para voltarmos a Williams, a respeito do papel da linguagem. Pois as falas "reais" das pessoas diante das câmeras também foram escritas e ensaiadas. Aquilo que vemos como produto final no filme, segundo o diretor, além de ser resultado do trabalho de edição e montagem, é fruto de um trabalho colaborativo que mescla e às vezes apaga as distinções e cria uma relação dialética entre roteiro e improvisação, espontaneidade e reportagem, depoimento e criação literária, estatística e sistema simbólico, ficção e documentário, experiência histórica e trabalho criativo. Num dos momentos de acuidade analítica e grande beleza do texto de Williams sobre The Big Flame, ele observa que, ao filmar os trabalhadores que na vida real haviam participado da greve derrotada, Loach cria a oportunidade para que "as pessoas envolvidas na produção tentem melhor compreender e formular suas próprias condições, desenvolvendo uma consciência reflexiva de suas situações ao fazerem parte da realização do filme". ${ }^{21}$ Tal experiência daria frutos no futuro da carreira do diretor: algumas das cenas mais marcantes de seus filmes - como a da coletivização das terras em Terra e Liberdade ou da discussão entre Carla, seu namorado escocês e os camponeses que na vida real participaram das lutas da Revolução na Nicarágua em A canção de Carla (1997) - podem ser justamente elogiadas tanto pelo emprego épico do discurso narrativo e argumentativo em cena, como também por uma mudança radical do sentido do trabalho realizado para aqueles envolvidos na produção. ${ }^{22}$

Mas não se trata tampouco da tentativa de capturar a experiência "imediata", anterior à sua conceitualização, pois a pesquisa também envolve, como insistimos anteriormente, um recorrido pelo vasto repertório da arte política que é transformado num conjunto de "procedimentos retóricos" que ajudam a formular as teses do filme para o diretor, o público e os próprios "atores". No caso de The Big Flame, há pelos menos três procedimentos que merecem atenção: o emprego épico de comentários em voice-over, que comentam e ampliam a ação; o uso de uma canção cantada por um marinheiro americano sobre um dos líderes da IWW, que dá à ação encenada alcance internacional enquanto enfatiza o papel da arte militante na luta política; e, finalmente, o papel do personagem de um juiz, numa sequência que se utiliza das técnicas de agitprop do teatro tribunal, em que o personagem elogia o marxismo como ferramenta intelectual na universidade, mas condena seu uso político na mão de trabalhadores. Em cada cena individual e no conjunto, aquilo que é frequentemente descrito como o estilo "simples", "direto" e "realista" do diretor é, na verdade, o resultado de um naturalismo experimental e investigativo, resultado de uma tensão entre fato histórico e elaboração artística, entre o papel do escritor que elabora o roteiro filmado e a contribuição 
dos "atores" que colaboram com a criação literária ao terem espaço para incluir nas falas seus próprios depoimentos e experiências.

Quase cinquenta anos depois, a "grande chama" sofreu diversos revezes e derrotas e seu papel na economia da narrativa dos filmes de Loach frequentemente sofreu uma diminuição: em Eu, Daniel Blake ela sobrevive numa restrita rede de solidariedade que envolve vizinhos, colegas de trabalho, uma das assistentes sociais. Novamente será a montagem - que nesta altura já podemos eleger como um dos procedimentos centrais do qual dependem os efeitos do filme - que irá contrastar a opacidade do início e a humanidade das relações humanas que sobrevivem a duras penas. Essa camada de significados ganha, entretanto, uma potente ampliação na sequência em que Blake picha as paredes do prédio da Previdência exigindo atenção, na qual as ressonâncias coletivas do desejo do novo ganham eloquência a partir da participação de uma torcida composta de atores e passantes da "vida real", inflamados com o ato de rebeldia. Já o diagnóstico do cineasta em 1969 fica cada vez mais atual: quando indagado sobre a origem de sua formação política - e indiretamente sobre a gênese do seu método de filmagem - Loach afirmou: "Em 1969 [após a greve de Liverpool e a adoção in toto pelo governo Trabalhista do plano econômico dos Conservadores], as esperanças sobre o que um governo Trabalhista poderia fazer na Inglaterra foram rapidamente destruídas. O que percebemos foi que a socialdemocracia a os políticos Trabalhistas estavam simplesmente agindo em nome das elites, protegendo os interesses do capital". Aqui está a origem da "grande chama".

Notas

1. Ver, por exemplo, os ensaios de Fredric Jameson, A cultura do dinheiro: ensaios sobre a globalização. Petrópolis: Vozes, 2001.

2. Ver, por exemplo, Graham Fuller (ed.), Loach on Loach. London: Faber and Faber, 1998, p. 9.

3. Sobre a avaliação do próprio Williams acerca do livro ver Raymond Williams, Politics and Letters: Interviews with New Left Review. London: Verso, 1981, pp. 187-234.

4. Ver Chris Harman, The Fire Last Time: 1968 and After. London, Chicado \& Sidney: Bookmarks, 1998, pp.223-270.

5. Peter Szondi, Teoria do drama moderno. São Paulo: Cosac \& Naify, 2003.

6. Para alguns dos melhores ensaios sobre os filmes da "New Wave" inglesa ver John Hill, "Working-class realism and sexual reaction: some theses on the British New Wave" in James Curran \& Vincent Porter (eds.), British Cinema History. New Jersey: Barnes \& Noble Books, 1983.

7. Para um estudo da crítica inglesa sobre os filmes na época de seus lançamentos ver B. F. Taylor, The British New Wave. Manchester \& New York: Manchester University Press, 2006.

8. Peter Graham, The Abortive Renaissance: Why are Good British Films so Bad? London: AXLE Publications, 1963.

9. Idem, p. 11. 
10. Ver Dominic Sandbrook, White Heat: a History of Britain in the Swinging Sixties. London: Abacus, 2007, pp.5-6.

11. Ver Raymond Williams, Politics and Letters: Interviews with New Left Review. London \& New York: Verso, 1981, pp. 187-234. Para uma avaliação esclarecedora sobre o contexto de publicação do livro e das intervenções de Williams na área dos estudos de teatro, ver o prefácio de Iná Camargo Costa à edição brasileira de Tragédia Moderna. Iná Camargo Costa, "Tragédia no século XX" in Raymond Williams, Tragédia Moderna. São Paulo: Cosac \& Naify, 2002, pp. 7-21.

12. Raymond Williams, idem, p. 204.

13. Raymond Williams, "A defence of realism" in What I Came to Say. London: Hutchison Radius, 1989, p. 234.

14. Essa também era a visão de Eisenstein sobre o projeto naturalista, como fica evidente em sua cuidadosa leitura de Zola. Ver Sergei Eisenstein, Non-Indifferent Nature: Film and the Structure of Things. Cambridge: CUP, 1988. Como procuro demonstrar neste ensaio, para Loach a montagem, feita sem alarde, também é procedimento formal central.

15. Diz Brecht a respeito do conceito de realismo: "Nosso conceito de realismo deve ser amplo e político, livre de restrições estéticas e independente de convenções. Realista significa: explicitar as relações causais que dominam a vida social / mostrar que o ponto de vista dos vencedores como o ponto de vista dos vencedores / escrever do ponto de vista da classe que tem as melhores e mais amplas soluções para os problemas mais urgentes que afligem a sociedade / enfatizar as dinâmicas do desenvolvimento / concreto mas encorajando a abstração". Ver Bertolt Brecht, "The popular and the realistic" in John Willett (ed.) Brecht on Theatre. London: Methuen Drama, 1964, p. 109.

16. Raymond Williams, idem ibid, p. 234.

17. Ver Douglas Estevam, Iná Camargo Costa, Rafael Villas Bôas (eds.), Agitprop: Cultural Política. São Paulo: Expressão Popular, 2015.

18. Chris Harman, idem, p. 225.

19. Williams, idem, p. 234.

20. Ver "Making Kes", documentário disponível na cópia do filme Kes lançado pela Criterion Collection.

21. Williams, idem, p. 238.

22. Um dos pontos centrais das teses de Walter Benjamin em "O autor como produtor": não importa o quão progressistas as teses de uma obra possam ser, ela só será politicamente útil se modificar as condições de trabalho de seus produtores em sentido socialista. Ver Walter Benjamin, "O autor como produtor" in Obras Escolhidas. São Paulo: Brasiliense, 1993.

\section{Referências}

CURRAN, James \& Porter, Vincent (eds.). British Cinema History. New Jersey: Barnes \& Noble Books, 1983.

BENJAMIN, Walter. Obras Escolhidas. São Paulo: Brasiliense, 1993.

EISENSTEIN, Sergei. Non-Indifferent Nature: Film and the Structure of Things. Cambridge: CUP, 1988.

ESTEVAM, Douglas, VOSTA, Iná, VILLAS BÔAS, Rafael (eds.). Agitprop: Cultural

Política. São Paulo: Expressão Popular, 2015 
FULLER, Graham (ed.). Loach on Loach. London: Faber and Faber, 1998.

HARMAN, Chris. The Fire Last Time: 1968 and After. London, Chicado \& Sidney: Bookmarks, 1998.

JAMESON, Fredric. A cultura do dinheiro: ensaios sobre a globalização. Trad. de Maria Eliza Cevasco e Marcos César de Paulo Soares. Petrópolis: Vozes, 2001.

SANDBROOK, Dominic. White Heat: a History of Britain in the Swinging Sixties. London: Abacus, 2007.

SZONDI, Peter. Teoria do drama moderno. São Paulo: Cosac \& Naify, 2003.

TAYLOR, B. F. The British New Wave. Manchester \& New York: Manchester University Press, 2006.

WILLIAMS, Raymond. Politics and Letters: Interviews with New Left Review. London: Verso, 1981.

What I Came to Say. London: Hutchison Radius, 1989.

Tragédia Moderna. São Paulo: Cosac \& Naify, 2002.

Recebido em: 23/10/2017

Aceito em: 22/05/2018 